\title{
Experimental study and numerical simulation of hydrogen/isobutane permeation and separation using MFI-zeolite membrane reactor
}

\author{
Patrice Ciavarella $^{\text {a }}$, Hichem Moueddeb ${ }^{\text {a }}$, Sylvain Miachon ${ }^{\text {a }}$, Koffi Fiaty ${ }^{\mathrm{b}}$, \\ Jean-Alain Dalmon ${ }^{\mathrm{a}, *}$ \\ ${ }^{a}$ Institut de Recherches sur la Catalyse, CNRS, 2, Av. A. Einstein, 69626 Villeurbanne Cedex, France \\ ${ }^{\mathrm{b}}$ Laboratoire d'Automatique et de Génie des Procédés, UPRESA CNRS Q 5007, UCB-CPE Lyon, 43 Bd du 11 Nov. 1918, \\ 69622 Villeurbanne Cedex, France
}

\begin{abstract}
A composite alumina-MFI-zeolite membrane has been prepared by a pore-plugging method. Transport through this membrane is controlled by molecular size and adsorption properties, as expected for a defect-free zeolite composite layer.

Single gas transport was studied for hydrogen and isobutane. In the studied temperature range, (323-723 K) for isobutane and $(277-723 \mathrm{~K})$ for hydrogen, transports were activated. Isobutane exhibited a flux maximum at $450 \mathrm{~K}$, whereas hydrogen flux declined with temperature.

These different permeation behaviors were modeled using Maxwell-Stefan equations taking into account only surface diffusion. Activation energies were obtained from the model by fitting the experimental data. They were calculated to be $31 \mathrm{~kJ} \mathrm{~mol}^{-1}$ for isobutane and $1.9 \mathrm{~kJ} \mathrm{~mol}^{-1}$ for hydrogen. The diffusion coefficients calculated at $323 \mathrm{~K}$ differed by four orders of magnitude.

Separation experiments with a mixture of hydrogen and isobutane in a 293-723 K temperature range were performed. Typical permeation behavior was observed for a mixture of weakly and strongly adsorbed molecules. At room temperature, hydrogen permeation was hindered by stronger adsorbed isobutane molecules in the micropores. $\mathrm{H}_{2} / i-\mathrm{C}_{4} \mathrm{H}_{10}$ separation experiments showed a separation factor of 25 at $723 \mathrm{~K}$, a typical temperature of the isobutane dehydrogenation in membrane reactors.
\end{abstract}

\section{Résumé}

Une membrane composite alumine-zéolithe MFI est préparée par une méthode de bouchage de pores. Le transport à travers la membrane est contrôlé par la taille des molécules et leurs propriétés d'adsorption, comme on peut s'y attendre dans une couche composite zéolithique sans défaut.

Le transport des gas purs est étudié pour l'hydrogène et l'isobutane. Dans les domaines de température étudiés, 323-723 K pour l'isobutane et $277-723 \mathrm{~K}$ pour l'hydogène, le transport de ces deux gaz est activé. Le flux d'isobutane présente un maximum à $450 \mathrm{~K}$, alors que celui d'hydrogène diminue avec la température.

Ces différents comportements en perméation sont modélisés en utilisant les équations de Maxwell-Stefan appliquées uniquement à la diffusion de surface. L'ajustement de l'équation du modèle aux données expérimentales permet d'obtenir les energies d'activation de diffusion. Celles-ci sont de $31 \mathrm{~kJ} \mathrm{~mol}^{-1}$ pour l'isobutane et de $1.9 \mathrm{~kJ} \mathrm{~mol}^{-1}$ pour l'hydrogène. Les coefficients de diffusion calculés à $323 \mathrm{~K}$ sont dans un rapport de $10^{4}$.

Des expériences de séparation hydrogène/isobutane sont effectuées dans une gamme de température de 293 à $723 \mathrm{~K}$. Il a été observé un comportement en perméation typique d'un mélange binaire de molécules gazeuses fortement et faiblement

*Corresponding author. Fax: +33-4-7244-5399.

E-mail address: dalmon@ catalyse.univ-lyon.fr (J.-A. Dalmon).

0920-5861/00/\$ - see front matter @2000 Elsevier Science B.V. All rights reserved.

PII: S 0920-5861(99)00283-7 
adsorbées. À température ambiante, la perméation d'hydrogène est gênée par les molécules d'isobutane fortement adsorbées dans les micropores. Un facteur de séparation hydrogène/isobutane de 25 est obtenu à $723 \mathrm{~K}$, température typique de la déshydrogénation de l'isobutane en réacteur membranaire. (02000 Elsevier Science B.V. All rights reserved.

Keywords: Zeolite membrane; MFI; Gas separation; Adsorption; Modeling

\section{Introduction}

The dehydrogenation of isobutane is currently of major importance because of the growing demand of isobutene as an intermediate for the production of methyl-tertiary butyl ether (MTBE), a gasoline octane enhancer.

Some $\mathrm{C}_{4}$ dehydrogenation processes have been developed using a fluidized bed of platinum catalyst in the UOP process [1], or a fixed bed of a chromium based catalyst in the STAR process (Phillips petroleum) [2]. These catalytic processes are limited by the thermodynamics or kinetics of isobutane dehydrogenation reactions. Reasonable yields require higher temperatures which causes rapid deactivation of the catalyst due to coke formation. This in turn necessitates regenerating the catalyst frequently. To improve catalyst stability, some processes use a hydrogen feed, although this limits the conversion.

However, it is well known that removing a product from a reversible reaction system shifts the equilibrium towards the products. In fact, this is the main advantage in using a membrane reactor. Indeed continuous and selective hydrogen removal can either improve olefins yields, or allows lower operating temperatures for the same conversions. Experimental studies illustrating such an improvement on isobutane dehydrogenation have been reported [3-5].

Catalyst deactivation has been avoided by feeding hydrogen on the reaction side of the membrane [6,7]. Thus in order to keep high yields, it is even more important to use a membrane that is highly permselective towards hydrogen.

Research efforts into increasing membrane selectivity, permeability and stability in gas separation processes have led to a new and very attractive solution: zeolite membrane [8,9]. Besides stability, the main advantage of zeolites as membrane material is uniform pore-size distribution.

Until recently, neither defect-free zeolite membranes nor a quantitative theory of gas diffusion/ permeation in such membranes were available [10]. In recent years, however, several groups have reported in the literature preparations of high quality zeolite membranes: MFI [11-20], mordenite [21], Y-type [22], A-type [23-25] and ferrierite [26].

Among the small range of available zeolite membranes, MFI membranes on $\alpha$-alumina or stainless steel support present the most reproducible characterization and permeance data. Zeolite MFI membranes (silicalite and ZSM-5) with 10-ring channels have a pore diameter of about $0.55 \mathrm{~nm}$. This means that selective separations using differential adsorption behavior or molecular sieving can be carried out.

In order to predict the permeation and separation behavior, macroscopic models are needed to describe, for different operating conditions, the flux through microporous membranes. Although various models have been proposed for the determination of single gas diffusion [14,27-30], the transport in the zeolite pores is still poorly understood.

The present work was preceded by simple modeling aimed at characterizing the membrane from the viewpoint of permeating gases [13]. In the present study, the preparation and characterization of a defect-free zeolite composite MFI-alumina membrane is summarized. Separation experiments with a mixture of hydrogen and isobutane diluted in nitrogen were carried out as a function of temperature. A model derived from Barrer [27] is introduced for single gas transport through micropores assuming a Langmuir isotherm. The model parameters (activation energies and intrinsic diffusion constants) are estimated with experimental hydrogen and isobutane single flux.

\section{Experimental}

\subsection{Composite alumina-MFI membrane}

A detailed description of the composite membrane preparation can be found in previous papers 
[11,13,31]. The macroporous alumina has a top layer pore size of $200 \mathrm{~nm}$ (Membralox T1-70 [32], purchased from SCT/US Filter). The precursor was a clear solution of tetrapropylammonium hydroxide (TPAOH, $1 \mathrm{M}$ solution from Aldrich) and silica (Aerosil Degussa 380) [11].

This single-step preparation protocol is now well mastered. It has been repeated about 100 times with more than 95 successes, i.e. produced a defect-free membrane as related later.

\subsection{Characterizations}

The membrane has been characterized using routine techniques, i.e. SEM (Hitachi S800), XRD, pore size distribution from the $\mathrm{N}_{2}$ adsorption isotherm using the DFT method (Micromeritics ASAP 2000M). For more information, results of the physical characterizations are published in a previous paper $[12,13]$.

Hydrogen permeation versus pressure at high temperature and hydrogen $/ n$-butane separation versus temperature were performed to exclude defective membranes.

\subsection{Transport measurements}

The membrane was placed in a stainless steel module equipped with temperature regulation. Graphite cylindrical rings were used as seals between the membrane and the module. The active membrane area is ca. $22 \mathrm{~cm}^{2}$.

Gas permeation measurements were performed in the $277-723 \mathrm{~K}$ range for hydrogen and isobutane. Gas flows and feed composition were controlled by mass flow controllers (MFC Brooks, type 5850TR and 5850E).

Isobutane flux was investigated by steady state permeation measurements by a Wicke-Kallenbach modified method with nitrogen as diluting and sweep gas. Multicomponent permeation measurement was performed by the same technique, with a mixture of hydrogen and isobutane diluted in nitrogen $(12,15$ and $73 \mathrm{vol} \%$, respectively).

Hydrogen flux was measured in pure gas experiments. As a matter of fact, this gas would be very sensible to diluting, because it is a weakly adsorbed molecule. The use of any other gas would reduce hydrogen flux due to competitive adsorption. Of course, the accuracy of the measurement requires perfectly checked defect-free membranes. Indeed, transmembrane pressure differences would lead to viscous flow through defects, if any [17,33,34]. This last method was not applicable to isobutane permeation due to the very low fluxes, only accurately measurable with chromatographic techniques.

During all the Wicke-Kallenbach type experiments, retentate and permeate pressures were set to $125 \mathrm{kPa}$. The feed and sweep gas (nitrogen) flow was $5.4 \times 10^{-5} \mathrm{~mol} \mathrm{~s}^{-1}$.

A gas chromatograph (Shimadzu, GC-14A) using both TCD and FID detectors measured feed, retentate and permeate concentrations.

The permeation and separation experiments were performed at steady-state temperature and flow rates. Between measurements, the temperature was carefully increased at a heating rate of $1 \mathrm{~K} \mathrm{~min}^{-1}$. Before each series of measurements over a given temperature range for each, the membrane module was heated to $673 \mathrm{~K}$ while flushing with nitrogen. All measurements were carried out reversibly.

\subsection{Permeance, permselectivity and separation factor}

Permeance $\prod_{i}$ was defined as the molar flow of the species $i$ with respect to the membrane surface area and pressure difference $\left(\mathrm{mol} \mathrm{m}^{-2} \mathrm{~s}^{-1} \mathrm{~Pa}^{-1}\right)$. Permselectivity $\alpha_{i / j}$, of gas $i$ over gas $j$, was calculated as the ratio of the two pure gas permeances. Separation factor $S_{\mathrm{f}}$ was calculated as an enrichment factor in the permeate as compared to the feed composition ratio [30].

\section{Model of single gas transport through microporous material}

\subsection{Micropore diffusion theory}

Twenty-five years ago Weisz [35] introduced the term "configurational" diffusion for the migration/diffusion in micropores. It is acknowledged that, qualitatively, at low occupancy, the transition from the Knudsen diffusion regime to the configurational 
regime occurs when the pore size approaches the molecular size. Molecules inside zeolites, however, may not be as free as in Knudsen diffusion where the effect of the potential field of the solid surface is minimal. In zeolites, molecules may never completely escape from the potential field of the lattice even if the pore size is larger than the molecular size.

Several authors proposed a model for transport in microporous membrane based on different kinds of diffusion [14,36-39]. Barrer [27] showed that the external crystal surface plays an important role in the transport of gases through the material. In the case of a membrane, Bakker et al. [14] added in their model a gas translation contribution at low occupancy.

In this work, zeolitic gas transport has been treated as only surface diffusion in the same way as Barrer [27] for crystals.

\subsection{General description of single gas transport}

Diffusional flux is globally described in two ways, based on the Fickian (Eq. (1)) or the Maxwell-Stefan (Eq. (2)) approach [29].

$J=-D_{\mathrm{F}}(q) \frac{\mathrm{d} q}{\mathrm{~d} z}$

$J=-B_{\mathrm{C}}(q) q \frac{\mathrm{d} \mu}{\mathrm{d} z}$,

where $J$ is the molar flux $\left(\mathrm{mol} \mathrm{m}^{-2} \mathrm{~s}^{-1}\right), D_{\mathrm{F}}(q)$ the Fickian diffusion constant $\left(\mathrm{m}^{2} \mathrm{~s}^{-1}\right), q$ the concentration of the mobile species in the micropores $\left(\mathrm{mol} \mathrm{m}{ }^{-3}\right),(\mathrm{d} q / \mathrm{d} z)$ the concentration gradient, $B_{\mathrm{C}}(q)$ the mobility of the species $\left(\mathrm{mol} \mathrm{Pa}^{-1} \mathrm{~m}^{-1} \mathrm{~s}^{-1}\right)$, and $(\mathrm{d} \mu / \mathrm{d} z)$ is the chemical potential gradient.

The Fickian approach assumes the concentration gradient to be the driving force for the transport. More precisely, the Maxwell-Stefan equation (Eq. (2)) considers chemical potential gradient to be the driving force.

In order to describe permeation by Fickian diffusion, $D_{\mathrm{F}}(q)$ is related to an intrinsic diffusivity (or a Maxwell-Stefan diffusivity) $D_{0}(q)$ by a Darken-type equation:

$D_{\mathrm{F}}(q)=\Gamma D_{0}(q)$,

where $\Gamma=\mathrm{d} \ln P / \mathrm{d} \ln q$ is the thermodynamic factor (or the Darkian factor), $R$ the gas constant
( $\mathrm{J} \mathrm{mol}^{-1} \mathrm{~K}^{-1}$ ) and $T$ is the temperature (K). This thermodynamic factor converts the chemical potential gradient into a gradient representing surface occupancy.

\subsection{Concentration dependency of the thermodynamic factor}

Sorption in the micropores can be adequately described for a large number of cases by the Langmuir isotherm. Let us recall that the Langmuir isotherm considers that the adsorption of a molecule is not influenced by other adsorbed molecules and that all sites are equivalent.

For one component, the Langmuir isotherm is given by

$\theta=\frac{q}{q_{\mathrm{sat}}}=\frac{K P}{1+K P}$,

where $\theta$ is the fractional surface occupancy (also referred as coverage), $q_{\text {sat }}$ the sorption capacity of the microporous material $\left(\mathrm{mol} \mathrm{m}^{-3}\right), K$ the adsorption equilibrium constant or Langmuir parameter $\left(\mathrm{Pa}^{-1}\right)$ and $P$ is the pressure (Pa).

The Langmuir isotherm can be used to express the thermodynamic factor

$\Gamma=\frac{q_{\mathrm{sat}}}{q_{\mathrm{sat}}-q}=\frac{1}{1-\theta}$.

In the case of zero coverage, both diffusion constants (Fick and Maxwell-Stefan) become equal. Substituting Eqs. (3) and (5) in Eq. (1), and assuming intrinsic diffusion constant $D_{0}$ to be independent of concentration, the following expression for the flux is obtained:

$\int_{0}^{L} J \mathrm{~d} z=-D_{0} \int_{q_{\mathrm{R}}}^{q_{\mathrm{P}}} \frac{q_{\mathrm{sat}}}{q_{\mathrm{sat}}-q} \mathrm{~d} q$,

where $q_{\mathrm{P}}$ and $q_{\mathrm{R}}$ are the steady-state concentrations at the permeate and the retentate side, respectively, and $L$ is the effective thickness of the composite membrane.

\subsection{Integration of the equation of single gas transport}

Eq. (7) is obtained after integration of Eq. (6):

$$
J=\frac{D_{0} q_{\mathrm{sat}}}{L} \ln \left[\frac{q_{\mathrm{sat}}-q_{\mathrm{P}}}{q_{\mathrm{sat}}-q_{\mathrm{R}}}\right] .
$$


If the Langmuir isotherm is assumed, the $q_{\mathrm{s}}$ and $q_{\mathrm{p}}$ concentrations can be expressed as functions of pressure:

$J=\frac{D_{0} q_{\mathrm{sat}}}{L} \ln \left[\frac{1+K P_{\mathrm{R}}}{1+K P_{\mathrm{P}}}\right]$,

where $P_{\mathrm{P}}$ and $P_{\mathrm{R}}$ are the pressures at permeate and retentate sides, respectively.

Eq. (8) is similar to the equation derived by Kapteijn et al. [37] for single gas transport through a supported zeolite membrane.

\subsection{Transport temperature dependency}

$D_{0}$ is assumed to be occupancy-independent as the free diameter of the pore is of the same order as the critical diameter of the sorbate molecule [40]. Its temperature dependency should satisfy an Arrhenius-type relation (Eq. (9)):

$D_{0}=D_{0}^{\infty} \exp \left[\frac{-E_{\mathrm{D}}}{R T}\right]$,

where $E_{\mathrm{D}}$ is the diffusional activation energy $\left(\mathrm{kJ} \mathrm{mol}^{-1}\right)$ and $D_{0}^{\infty}$ is the intrinsic diffusivity at infinite temperature.

The temperature dependency of the Langmuir parameter $K$ can be correlated by a Van't Hoff-type relation (Eq. (10)), assuming $\Delta U_{\text {ads }} \cong \Delta H_{\text {ads }}$ :

$$
\begin{aligned}
K & =K_{0} \exp \left[\frac{-\Delta U_{\text {ads }}}{R T}\right] \\
& =\exp \left[\frac{\Delta S_{\text {ads }}}{R}-\frac{\Delta H_{\text {ads }}}{R T}\right] .
\end{aligned}
$$

Here $\Delta U_{\text {ads }}$ is the internal adsorption energy $\left(\mathrm{J} \mathrm{mol}^{-1}\right.$ $\left.\mathrm{K}^{-1}\right), \Delta S_{\text {ads }}$ the adsorption entropy $\left(\mathrm{J} \mathrm{mol}^{-1} \mathrm{~K}^{-1}\right)$ and $\Delta H_{\text {ads }}$ is the differential adsorption enthalpy $\left(\mathrm{J} \mathrm{mol}^{-1}\right)$, for $K$ given in $\mathrm{atm}^{-1}$.

\subsection{Single gas transport in microporous membrane}

The equation of the single gas flux through a microporous membrane can be obtained by substituting Eqs. (9) and (10) in Eq. (8). The intrinsic diffusion constant is corrected by a factor $(\epsilon / \tau)$ to take into account the geometrical properties of the composite membrane. $\epsilon$ and $\tau$ are the porosity and the tortuosity of the composite membrane, respectively. ${ }^{1}$

$$
\begin{aligned}
J= & \frac{c_{\text {sat }} \rho_{\mathrm{MFI}} \varepsilon D_{0}^{\infty}}{\tau L} \ln \\
& \times\left[\frac{1+P_{\mathrm{R}} \exp \left(\left(\Delta S_{\text {ads }} / R\right)-\left(\Delta H_{\text {ads }} / R T\right)\right)}{1+P_{\mathrm{P}} \exp \left(\left(\Delta S_{\text {ads }} / R\right)-\left(\Delta H_{\text {ads }} / R T\right)\right)}\right] \\
& \exp \left[\frac{-E_{\mathrm{D}}}{R T}\right] .
\end{aligned}
$$

Eq. (11) gives the flux of a single component through a composite microporous membrane. This equation can be divided into three parts. The left hand part is temperature independent as far as $c_{\mathrm{sat}}$ is temperature independent. The second term decreases with temperature due to the fact that retentate pressure is higher than permeate pressure. The right hand term increases with temperature. According to parameters values $\left(\Delta S_{\mathrm{ads}}, \Delta H_{\mathrm{ads}}, E_{\mathrm{D}}\right)$, the variation of flux with temperature is not easily foreseen.

Compared to our previous and more simple model approach [13], the main improvement lies in the second term. What used to be a simple diffusion constant includes now an adsorption contribution. At low differential enthalpy, Eq. (11) tends to our previous description.

\subsection{Composite membrane parameters}

The single gas stationary flux through a composite MFI membrane, $J$, can be described adequately by Eq. (11) if sorption follows the Langmuir isotherm. The porosity $\epsilon$ and tortuosity $\tau$ of the composite membrane have been evaluated earlier, taking into account both support and zeolite parameters [13]. The effective layer thickness of the composite membrane, $L$, has been determined with the same approach used in the same paper. Adsorption data employed in this study were obtained from Bakker et al. [14] for hydrogen, and Millot et al. [41] for isobutane. Comparable results have been obtained for isobutane adsorption in silicalite-1 [42-44]. Table 1 gives the membrane geometric parameters and Table 2 the adsorption data

\footnotetext{
${ }^{1}$ In adsorption measurements the amount of gas adsorbed at saturation is generally related to a weight of porous medium $c_{\text {sat }}$ $\left(\mathrm{mol} \mathrm{kg}^{-1}\right)$, that is why $q_{\mathrm{sat}}\left(\mathrm{mol} \mathrm{m}^{-3}\right)$ was replaced by $c_{\mathrm{sat}} \rho_{\mathrm{MFI}}$ ( $\rho_{\text {MFI }}$ being the zeolite density).
} 
Table 1

Geometric parameters of the composite MFI-alumina membrane

\begin{tabular}{llll}
\hline Porosity & Tortuosity & $\begin{array}{l}\text { Effective thickness } \\
(\mu \mathrm{m})\end{array}$ & $\begin{array}{l}\text { MFI density } \\
\left(\mathrm{kg} \mathrm{m}^{-3}\right)\end{array}$ \\
\hline 0.075 & 1.2 & 3 & 1.7 \\
\hline
\end{tabular}

Table 2

Equilibrium adsorption properties of hydrogen and isobutane in silicalite-1

\begin{tabular}{llll}
\hline Gas & $\begin{array}{l}\Delta S_{\mathrm{ads}} \\
\left(\mathrm{J} \mathrm{mol}^{-1} \mathrm{~K}^{-1}\right)\end{array}$ & $\begin{array}{l}-\Delta H_{\mathrm{ads}} \\
\left(\mathrm{kJ} \mathrm{mol}^{-1}\right)\end{array}$ & $\begin{array}{l}c_{\mathrm{sat}} \\
\left(\mathrm{mol} \mathrm{kg}^{-1}\right)\end{array}$ \\
\hline Hydrogen $^{\mathrm{a}}$ & -43 & 5.9 & 5.4 \\
Isobutane $^{\mathrm{b}}$ & -89 & 44.7 & 1.5 \\
\hline
\end{tabular}

a Obtained from [14].

${ }^{\mathrm{b}}$ Obtained from [45].

in MFI material [14,41] for hydrogen and isobutane, respectively.

\section{Results}

The capacity of the membrane to be employed in a catalytic reaction in order to shift the equilibrium, and thus increase the yield, depends on its permeance and permselectivity. In fact, the membrane must selectively remove one product with a sufficient rate from the reaction side.

\subsection{Membrane defect characterization through gas permeations and separations}

Defects in the zeolite lattice are of great importance for the membrane separation performances. Some authors have indicated different techniques to characterize the defects in membranes $[12,13,15-17$, $33,36,41,46]$.

Our approach to this key problem was to use gas permeation and separations. The membranes were first tested for hydrogen/ $n$-butane separation versus temperature (Fig. 1).

The plot indicates high $n$-butane separation at room temperature $\left(S_{\mathrm{f}}=24\right)$ followed by an inversion after $500 \mathrm{~K}$. This is commonly explained as $n$-butane adsorption hindering hydrogen permeation [38]. At higher temperature, $n$-butane adsorption decreases and hydrogen is let through. This test was widely used

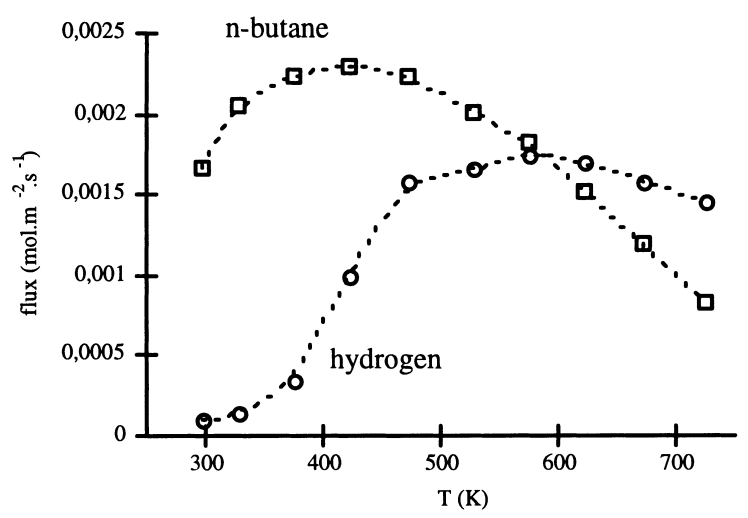

Fig. 1. Hydrogen $/ n$-butane separation versus temperature for the composite MFI-alumina membrane at $120 \mathrm{kPa}$ pressure (feed: $5.4 \times 10^{-5} \mathrm{mols}^{-1}$ with: $12 \%$ hydrogen, $15 \% \mathrm{n}$-butane and $73 \%$ nitrogen; sweep: $5.4 \times 10^{-5} \mathrm{~mol} \mathrm{~s}^{-1}$ of nitrogen at counter-current mode). Dashed lines are guides to the eyes.

here on many membranes to give an insight into their quality. Although this is not intended to be a perfect defect-detecting procedure, a really defective membrane does not pass this test.

Recently, a more careful approach based on the three gas transport mechanisms in the material exposed by Krishna [29] was developed [13].

"Bulk" or "molecular" diffusion occurs in macropores, and leads to viscous (Darcy) flow when a pore pressure difference is applied. Such large defects would give rise to a permeance pressure dependence. Fig. 2 shows, for example, that this is not the

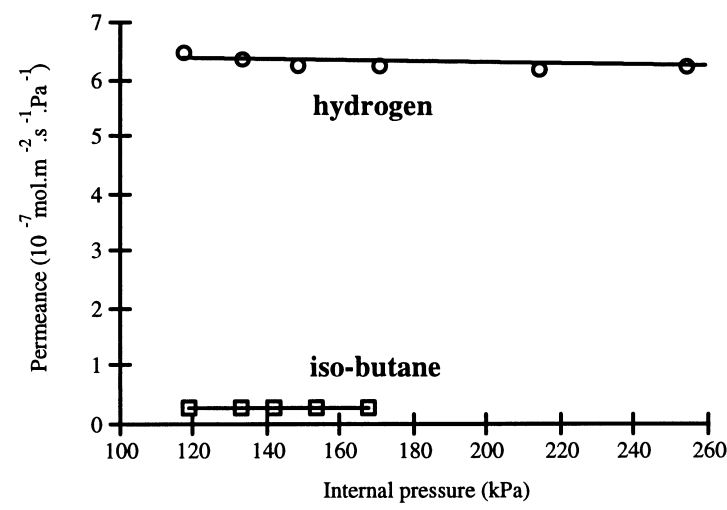

Fig. 2. Hydrogen and isobutane single gas permeance versus pressure temperature for the composite MFI-alumina membrane at $723 \mathrm{~K}(P=125 \mathrm{kPa})$. 
case for hydrogen or isobutane with the composite zeolite-alumina membrane prepared for this work. A temperature of $723 \mathrm{~K}$ was chosen because the experimental studies of isobutane dehydrogenation in a catalytic membrane reactor are normally performed at this temperature [3,5-7]. Previous calculations of viscous flow over diffusion ratio [13] have shown that convective contribution to transport is negligible (less than $3 \%$ of the global flux).

The second mechanism is Knudsen diffusion, which mainly occurs through mesopores. However in our case, the plot of permeance versus $T^{-1 / 2}$ was not linear. Moreover, hydrogen/isobutane permselectivity was found to be 24 at $723 \mathrm{~K}$. This figure is much higher than expected Knudsen permselectivity (5.4). This value and the non-linear $T^{-1 / 2}$ plot indicate that the mass transfer does not follow a Knudsen mechanism.

The third mechanism pointed out by Krishna is surface diffusion. This is an activated phenomenon that occurs predominantly in microporous materials. Should the membrane be defect-free, the gas transport would be exclusively controlled by such a mechanism. This was previously confirmed for the present composite membranes with hydrogen [13]. A calculation of the intrinsic diffusion constant at $323 \mathrm{~K}\left(D_{0}^{323 \mathrm{~K}}\right)$ has been included for a cleaner understanding.

\subsection{Hydrogen and isobutane permeation fits}

Figs. 3 and 4 present the experimental results of permeance for hydrogen and isobutane as a function

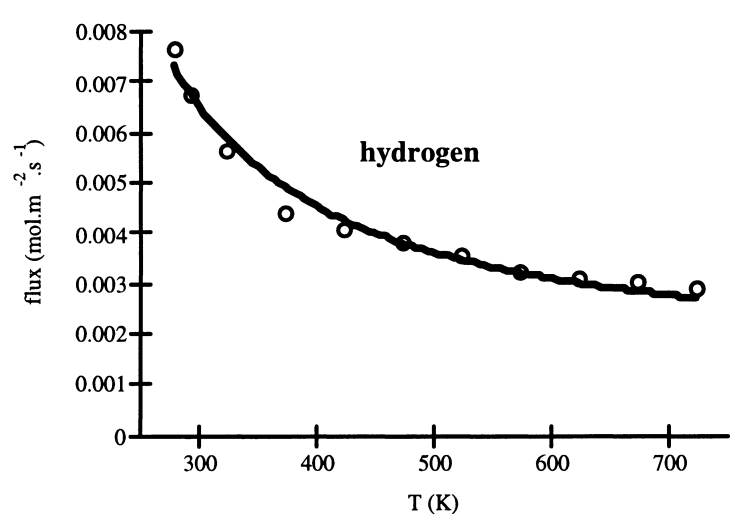

Fig. 3. Hydrogen pure gas flux through the MFI composite membrane versus temperature $\left(P=125 \mathrm{kPa}, \Delta P_{\text {tot }}=8 \mathrm{kPa}\right)$. The solid line is calculated from Eq. (11).

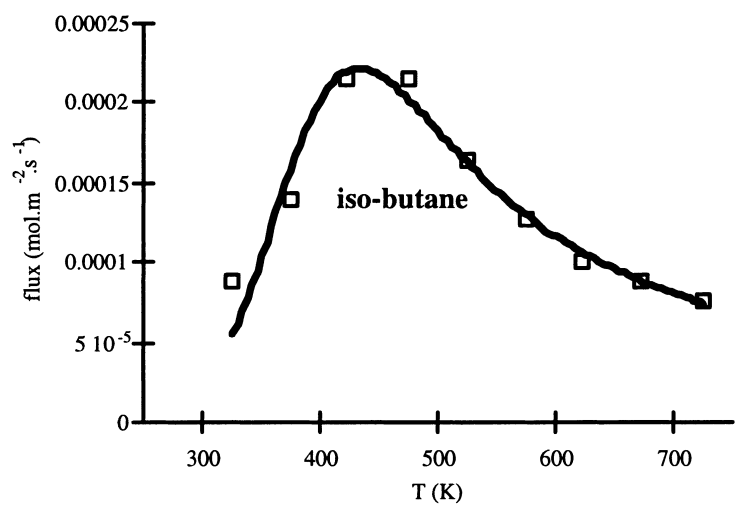

Fig. 4. Isobutane Wicke-Kallenbach type flux through the MFI composite membrane versus temperature $(P=125 \mathrm{kPa}$, $\left.\Delta P_{\text {tot }}=0 \mathrm{kPa}\right)$. The solid line is calculated from Eq. (11).

of temperature. The line gives the modeling fit based on Eq. (12). The two parameters fitted are the intrinsic diffusion constant $D_{0}^{\infty}$ and the diffusion activation energy $E_{\mathrm{D}}$ of hydrogen and isobutane. The corresponding values are given in Table 3.

Hydrogen flux decreases with temperature, whereas isobutane flux shows a maximum near $450 \mathrm{~K}$. This behavior difference is related to the adsorption capacity of both molecules in zeolite pores. Isobutane is much strongly adsorbed than hydrogen.

Isobutane diffusion activation energy is much higher than that of hydrogen. Consequently, at usual temperatures (for example $323 \mathrm{~K}$ in Table 3), the two diffusion coefficients differ by four orders of magnitude.

\subsection{Hydrogen/isobutane separation}

Hydrogen/isobutane separation experiments were performed as a function of temperature (Fig. 5). As for $n$-butane/hydrogen separation, stronger adsorption of the hydrocarbon hinders hydrogen diffusion through the membrane at room temperature.

Fig. 6 presents the hydrogen/isobutane separation factor $\left(S_{\mathrm{f}}\right)$. The separation factor can be expressed as

$S_{\mathrm{f}}=\left(\frac{x_{1}}{x_{2}}\right)_{\mathrm{P}}\left(\frac{x_{2}}{x_{1}}\right)_{\mathrm{F}}$,

with $x_{1}$ and $x_{2}$ being the molar fraction of components 1 and 2 in the feed (F) or the permeate (P).

The separation factor increases with temperature in the range studied (293-723 K). The best selectivity 
Table 3

Hydrogen and isobutane fit results

\begin{tabular}{|c|c|c|c|c|c|}
\hline \multirow[t]{2}{*}{ Gas } & \multicolumn{2}{|c|}{$D_{0}^{\infty}\left(10^{-8} \mathrm{~m}^{-2} \mathrm{~s}^{-1}\right)$} & \multicolumn{2}{|c|}{$E_{\mathrm{D}}\left(\mathrm{kJ} \mathrm{mol}^{-1}\right)$} & \multirow[t]{2}{*}{$D_{0}^{323 \mathrm{~K}}\left(\mathrm{~m}^{-2} \mathrm{~s}^{-1}\right)$} \\
\hline & Value & Error $^{a}$ & Value & Error $^{\mathrm{a}}$ & \\
\hline Hydrogen & 1.7 & \pm 0.1 & 1.9 & \pm 0.4 & $8.4 \times 10^{-9}$ \\
\hline Isobutane & 4.3 & \pm 0.6 & 31.3 & \pm 3.0 & $3.7 \times 10^{-13}$ \\
\hline
\end{tabular}

a Calculated from variance and covariance, with Student's $\alpha=5 \%$.

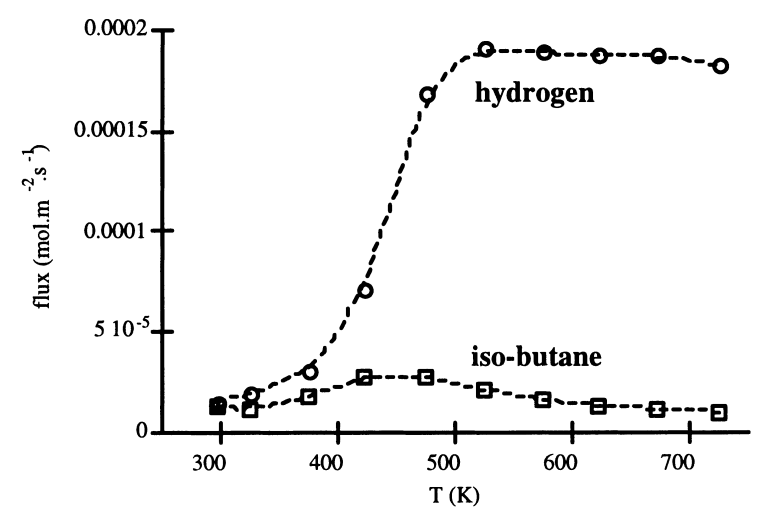

Fig. 5. Wicke-Kallenbach-type hydrogen/isobutane mixture separation: flux versus temperature for the composite MFI-alumina membrane $\left(P=125 \mathrm{kPa}, \Delta P_{\text {tot }}=0 \mathrm{kPa}\right.$; feed: $5.4 \times 10^{-5} \mathrm{~mol} \mathrm{~s}^{-1}$ with: $12 \%$ hydrogen, $15 \%$ isobutane and $73 \%$ nitrogen; sweep: $5.4 \times 10^{-5} \mathrm{~mol} \mathrm{~s}^{-1}$ of nitrogen at counter-current mode). Dashed lines are guides to the eyes.

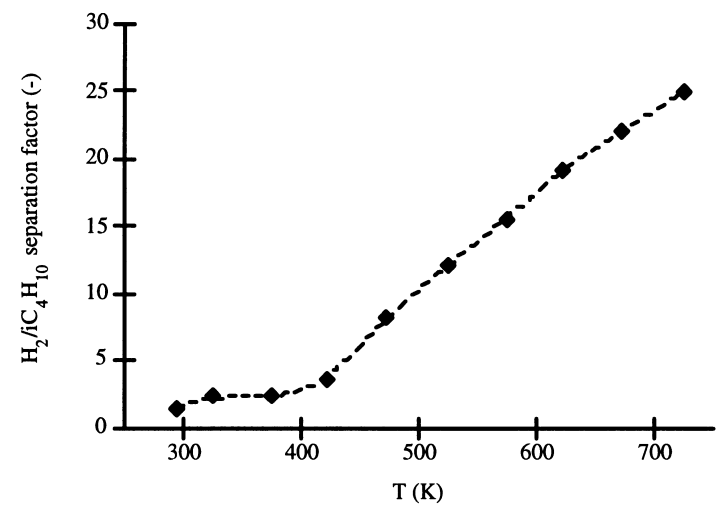

Fig. 6. Hydrogen/isobutane separation factor versus temperature for the composite MFI-alumina membrane $(P=125 \mathrm{kPa}$, $\Delta P_{\text {tot }}=0 \mathrm{kPa}$; feed: $5.4 \times 10^{-5} \mathrm{~mol} \mathrm{~s}^{-1}$ with: $12 \%$ hydrogen, $15 \%$ isobutane and $73 \%$ nitrogen; sweep: $5.4 \times 10^{-5} \mathrm{~mol} \mathrm{~s}^{-1}$ of nitrogen at counter-current mode). Dashed lines are guides to the eyes.
$\left(S_{\mathrm{f}}=25\right)$ is thus obtained at $723 \mathrm{~K}$, which corresponds to the isobutane dehydrogenation temperature in membrane reactors. This factor is strongly sweep gas flow rate dependent. We should underline that the present value was obtained with similar feed and sweep flow rates.

\section{Discussion}

\subsection{Membrane defect characterization through gas permeations and separations}

According to the protocol used in our pure gas permeation and separation experiments, the composite MFI-zeolite-alumina membrane was found to be defect-free, i.e. zeolite micropores control the transport properties of the membrane.

In the literature, several methods are used to determine the quality of zeolite membranes. The majority of these methods calculate permselectivities between two gases with the same adsorption behavior but different kinetic diameters [15-17,46]. Vroon et al. [16] used the $n$-butane/isobutane permselectivity at $473 \mathrm{~K}$ to test membrane defects. According to the authors, a defect-free membrane (high quality) is found when this permselectivity is higher than 10. Based on this criteria our membrane had a value of 18 .

Another technique involves permeating molecules with kinetic diameters slightly higher than the MFI channel (pore diameter: $d_{\mathrm{p}}=0.55 \mathrm{~nm}$ ). Among the molecules available for this test, sulfur hexafluoride (kinetic diameter: $d_{\mathrm{k}}=0.55 \mathrm{~nm}$ ) [33], 2,2-dimethylbutane $\left(d_{\mathrm{k}}=0.60 \mathrm{~nm}\right)$ [12,36], $o$-xylene $\left(d_{\mathrm{k}}=0.68 \mathrm{~nm}\right)$ [36] and 1,3,5-triisopropylbenzene $\left(d_{\mathrm{k}}=0.74 \mathrm{~nm}\right)$ [41] were tested. In these references, the authors noted a size exclusion for these molecules and thus concluded that their membranes 
were defect-free. Previously, 2,2-dimethylbutane permeance has been measured by us in our composite membranes [12]. A 45/55 molar ratio mixture of 2,2-dimethylbutane and $n$-hexane in nitrogen led to a permeate composition of $99.5 \%$ for the linear isomer at $373 \mathrm{~K}$.

One has to be careful when comparing results from the literature. Unfortunately, there does not seem to be a commonly accepted method to detect defects in zeolite membranes. Nevertheless, the results obtained in this work are in line with the literature. That is to say, according to both gas separation and size exclusion protocols, our membranes conform to the literature criteria for what is usually referred to as defect-free zeolite membranes.

\subsection{Gas permeation}

Fig. 4 shows a maximum in the isobutane flux as a function of temperature. This behavior is typical for the diffusion of linear hydrocarbons through zeolite $[36,39,46]$ but not for isobutane [14,33]. This plot shape is characteristic of transport described by surface diffusion when the activation energy of diffusion is smaller than the heat of adsorption. As the flux tends towards the maximum $(323-450 \mathrm{~K})$, isobutane mobility increases and occupancy decreases, meaning that a flux increases with temperature. Referring to Eq. (11), the flux maximum can be described as a balance between adsorption and activated surface diffusion. At high temperature the adsorbed phase concentration becomes limiting and permeance declines with temperature.

At lower temperatures than what is plotted in Fig. 4 isobutane exhibits a slightly higher flux. This behavior has not been taken into account in the present work as we deliberately limited the temperature range to $323-723 \mathrm{~K}$. This higher flux has been previously reported [41]. Using a bulk technique in powders, Zhu et al. [42] have alleged two adsorption sites for isobutane in silicalite-1. These authors have attributed this low-temperature behavior to isobutane filling of the intersections followed by filling of the zeolite channel.

In the literature, as opposed to light hydrocarbons $\left(\mathrm{C}_{1}-\mathrm{C}_{4}\right)$, isobutane flux (or permeance) often increases monotonously with temperature [14,33].
However, Burggraaf et al. [36] observed an isobutane permeance maximum at $410 \mathrm{~K}$ for low isobutane feed partial pressure $(8 \mathrm{kPa})$. This is close to our observations, i.e. a maximum at $450 \mathrm{~K}$ for a $15 \mathrm{kPa}$ feed partial pressure. For higher pressure $(100 \mathrm{kPa})$ they did not observe this maximum till $473 \mathrm{~K}$. Millot et al. [41] also noted a maximum for single isobutane permeation with isobutane pressure of 150 and $170 \mathrm{kPa}$, but at about $600 \mathrm{~K}$. It is clear from this short review that isobutane permeance variations against temperature depend largely on experimental conditions.

Hydrogen flux does not show a maximum in permeance in the temperature range studied (277-723 K), the flux decreasing continuously with temperature. This behavior is explained by the lower adsorption enthalpy of hydrogen, meaning that it is less adsorbed in the zeolite than isobutane. For weakly adsorbed components like hydrogen the maximum in permeance occurs at lower temperature [14].

Even for hydrogen, results presented in the literature also present large differences. Indeed, several authors $[14,33]$ reported a minimum in permeance versus temperature, whereas others give a maximum [36]. However, using the same membrane, we reported recently a continuous decrease in $\mathrm{H}_{2}$ flux up to temperatures as high as $873 \mathrm{~K}$ [13].

\subsection{Model}

The plots of hydrogen and isobutane flux versus temperature showed that the transport model based on the Maxwell-Stefan approach satisfactorily described the diffusion of these two molecules through our composite alumina-MFI-zeolite membrane. The flux of these two species, which have much different adsorption behaviors in MFI, can be expressed taking only surface diffusion into account. As opposed to Bakker et al. [14], adding a "gas translation diffusion" contribution was not necessary to describe the flux, notably at high temperature.

The isobutane activation energy for diffusion determined in this study was $31 \mathrm{~kJ} \mathrm{~mol}^{-1}$. This value is in good agreement with those obtained by Millot et al. (34 $\left.\mathrm{kJ} \mathrm{mol}^{-1}\right)$ using gas permeation techniques on the same type of membranes [41]. In that paper, microscopic measurements with the quasi-elastic neutron scattering (QENS) technique have been also 
performed, reporting a value of $17 \mathrm{~kJ} \mathrm{~mol}^{-1}$ for the isobutane $E_{\mathrm{D}}$. They concluded that in view of the large differences existing in the literature between macroscopic and microscopic techniques, the comparison between QENS and supported membrane data was quite satisfactory.

As far as isobutane diffusion coefficients is concerned, the value obtained here at $323 \mathrm{~K}\left(3.7 \times 10^{-13}\right.$ $\mathrm{m}^{-2} \mathrm{~s}^{-1}$ ) is in line with what can be calculated from the QENS work of Millot et al. $\left(3.2 \times 10^{-13} \mathrm{~m}^{-2} \mathrm{~s}^{-1}\right)$. Comparison with data from other studies $[14,33]$ seems not to be fruitful because of the difference in permeation behaviors and hence their deduced applied models. What is called elsewhere "activation energy" or "diffusion coefficient" may not mean the same as in this work.

An activation energy of $1.9 \mathrm{~kJ} \mathrm{~mol}^{-1}$ was obtained for hydrogen diffusion in the composite membrane. For this gas, as far as we know, few relevant values have been published. Using neutron scattering techniques on ZSM-5 [47] and $\mathrm{NaX}$ [48] zeolites, activation energies of approximately 1 (experimental range $115-200 \mathrm{~K})$ and $2 \mathrm{~kJ} \mathrm{~mol}^{-1}(70-150 \mathrm{~K})$ have been reported, respectively. These microscopic measurements are in good agreement with the results obtained here using a more global macroscopic method. A value obtained with a silicalite membrane by Bakker et al. [14] considering only the surface diffusion part of their model $\left(2.1 \mathrm{~kJ} \mathrm{~mol}^{-1}\right)$ is also in accordance with our work. Nevertheless, our value is clearly lower than that reported by this author when considering gas phase diffusion. Similar values i.e. $8-11 \mathrm{~kJ} \mathrm{~mol}^{-1}$ are also reported by Lovallo and Tsaptsis [20] and Bai et al. [33] in a global approach. However, as for isobutane, the completely different experimental variation against temperature of hydrogen permeation explains these discrepancies.

The hydrogen diffusion coefficient at $323 \mathrm{~K}$ obtained in the present work $\left(8.4 \times 10^{-9} \mathrm{~m}^{-2} \mathrm{~s}^{-1}\right)$ is difficult to compare due to a lack of results in the literature for this gas, hydrogen diffusion in zeolite membranes being much less studied than that for hydrocarbons. Once again, as far as we know, a single macroscopic work on MFI membrane [14] could provide a value of about $3 \times 10^{-8} \mathrm{~m}^{-2} \mathrm{~s}^{-1}$ as far as surface diffusion is concerned. Considering the great differences of modeling principles, this can be considered a reasonable match.

\subsection{Hydrogen/isobutane separation}

Temperature studies of this mixture separation is not very common in the literature for MFI membranes.

Hydrogen/isobutane separation behavior (Fig. 5) is typical of a mixture of strongly and weakly adsorbed species where the temperature has a drastic effect on the main permeating gas. At low temperature, hydrogen diffusion is hindered by the stronger adsorbed molecule, as already mentioned in the literature [12,38]. Thus mixture separation is mainly determined by competitive adsorption of mixture components. These results indicate that predicting multicomponent selectivity using only single gas permeation data is not appropriate.

The hydrogen/isobutane separation factor presented in Fig. 6 suggests that temperature is an important control parameter in optimizing separation performances. In the studied temperature range (293-723 K), the separation factor increased with temperature, where the best separation $\left(S_{\mathrm{f}}=25\right)$ was obtained at $723 \mathrm{~K}$. This value clearly demonstrates that an effective separation between hydrogen and isobutane can be realized at high temperature with our zeolite membrane. This suggests that isobutane dehydrogenation in zeolite membrane reactor can be considered. Modeling of this mixture adsorption transport is in progress. Data of competitive enthalpy and entropy for both gases are needed. Both experimental and simulation [29] approaches will be taken into account.

\section{Conclusion}

A zeolite-alumina composite membrane was found to be defect-free, i.e. the gas flux was controlled by micropores. Hydrogen and isobutane permeance experiments were carried out and the studied gases exhibited activated transport behavior. They presented remarkable permeation variations with temperature that were well fitted by the model based on Maxwell-Stefan equations. This model showed that it is possible to describe the flux through a microporous MFI membrane by assuming that the transport is only surface controlled as long as it is defect-free.

Isobutane activation energy and diffusion coefficient were found to be in line with results obtained elsewhere with microscopic and membrane techniques on 
the same materials. The same parameters were calculated for hydrogen and transient results obtained using the QENS technique were found to be comparable to the present work [41].

A value of 25 was found for the hydrogen/isobutane separation factor. Modeling of this mixture adsorption transport is in progress.

In order to go further in the defect characterization, and to try to get closer to the range of techniques used in the literature, an enlarged range of methods will be developed. In particular, $\mathrm{SF}_{6}$ permeation should give useful information.

\section{Nomenclature}

\begin{tabular}{|c|c|}
\hline$B_{\mathrm{C}}$ & $\begin{array}{l}\text { mobility of the species } \\
\left(\mathrm{mol} \mathrm{Pa}^{-1} \mathrm{~m}^{-1} \mathrm{~s}^{-1}\right)\end{array}$ \\
\hline$c_{\text {sat }}$ & $\begin{array}{l}\text { sorption capacity per weight of zeolite } \\
\left(\mathrm{mol} \mathrm{kg}^{-1}\right)\end{array}$ \\
\hline$D_{\mathrm{F}}$ & Fick diffusion coefficient $\left(\mathrm{m}^{2} \mathrm{~s}^{-1}\right)$ \\
\hline$D_{0}$ & intrinsic diffusion coefficient $\left(\mathrm{m}^{2} \mathrm{~s}^{-1}\right)$ \\
\hline$D_{0}^{\infty}$ & $\begin{array}{l}\text { intrinsic diffusion constant at infinite } \\
\text { temperature }\left(\mathrm{m}^{2} \mathrm{~s}^{-1}\right)\end{array}$ \\
\hline$D_{0}^{323 \mathrm{~K}}$ & $\begin{array}{l}\text { intrinsic diffusion constant at } 323 \mathrm{~K} \\
\left(\mathrm{~m}^{2} \mathrm{~s}^{-1}\right)\end{array}$ \\
\hline$d_{\mathrm{k}}$ & molecule kinetic diameter $(\mathrm{m})$ \\
\hline$E_{\mathrm{D}}$ & activation energy of diffusion $\left(\mathrm{J} \mathrm{mol}^{-1}\right)$ \\
\hline$\Delta H_{\mathrm{ads}}$ & differential adsorption entropy $\left(\mathrm{J} \mathrm{mol}^{-1}\right)$ \\
\hline$J_{i}$ & molar flux $\left(\mathrm{mol} \mathrm{m}^{-2} \mathrm{~s}^{-1}\right)$ \\
\hline$K$ & adsorption equilibrium constant $\left(\mathrm{Pa}^{-1}\right)$ \\
\hline$K_{0}$ & $\begin{array}{l}\text { limiting value of the adsorption } \\
\text { equilibrium constant }\left(\mathrm{Pa}^{-1}\right)\end{array}$ \\
\hline$L$ & effective membrane thickness (m) \\
\hline$P$ & pressure $(\mathrm{Pa})$ \\
\hline$P_{\mathrm{R}}$ & retentate pressure $(\mathrm{Pa})$ \\
\hline$P_{\mathrm{P}}$ & permeate pressure $(\mathrm{Pa})$ \\
\hline$\Delta P_{\text {tot }}$ & $\begin{array}{l}\text { total transmembrane pressure } \\
\text { difference }(\mathrm{Pa})\end{array}$ \\
\hline$q$ & $\begin{array}{l}\text { concentration of the mobile species } \\
\left(\mathrm{mol} \mathrm{m}^{-3}\right)\end{array}$ \\
\hline$q_{\text {sat }}$ & $\begin{array}{l}\text { sorption capacity per volume of zeolite } \\
\left(\mathrm{mol} \mathrm{m}^{-3}\right)\end{array}$ \\
\hline$q_{\mathrm{P}}$ & $\begin{array}{l}\text { concentration of the mobile species at the } \\
\text { permeate side } \\
\left(\mathrm{mol} \mathrm{m}^{-3}\right)\end{array}$ \\
\hline$q_{\mathrm{R}}$ & $\begin{array}{l}\text { concentration of the mobile species at the } \\
\text { retentate side }\left(\mathrm{mol} \mathrm{m}^{-3}\right)\end{array}$ \\
\hline
\end{tabular}

$\begin{array}{ll}R & \text { gas constant }\left(\mathrm{J} \mathrm{mol}^{-1} \mathrm{~K}^{-1}\right) \\ S_{\mathrm{f}} & \text { separation factor }(\text { dimensionless }) \\ \Delta S_{\text {ads }} & \text { adsorption entropy }\left(\mathrm{J} \mathrm{mol}{ }^{-1} \mathrm{~K}^{-1}\right) \\ T & \text { absolute temperature }(\mathrm{K}) \\ \Delta U_{\text {ads }} & \text { internal adsorption energy }\left(\mathrm{J} \mathrm{mol}^{-1}\right) \\ x_{i} & \text { molar fraction of species } i \\ z & \text { direction coordinate }(\mathrm{m})\end{array}$

Greek letters

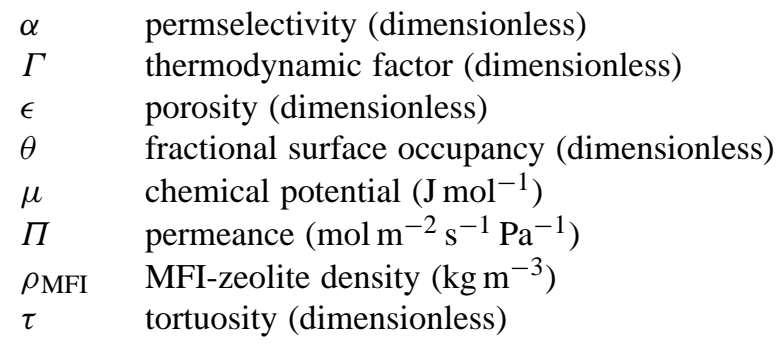

\section{References}

[1] P.R. Pujado, B.V. Vora, Hyd. Process. (1990) 65

[2] P.R. Sarathy, G.S. Suffridge, Hyd. Process. (1993) 43.

[3] Y. Zhu, R.G. Minet, T.T. Tsotsis, Catal. Lett. 18 (1993) 49.

[4] T. Matsuda, I. Koibe, N. Kubo, E. Kikuchi, Appl. Catal. A 96 (1993) 3.

[5] J. Shu, B.P.A. Grandjean, S. Kaliaguine, P. Ciavarella, A. Giroir-Fendler, J.A. Dalmon, Can. J. Chem. Eng. 75 (1997) 712.

[6] D. Casanave, A. Giroir-Fendler, J. Sanchez, R. Loutaty, J.-A. Dalmon, Catal. Today 25 (1995) 309.

[7] T. Ioannides, G.R. Gavalas, J. Membr. Sci. 77 (1993) 207.

[8] D.L. Wernick, E.J. Osterhuber, J. Membr. Sci. 22 (1985) 137.

[9] D.T. Haydrust, A.R. Paravar, Zeolites 8 (1988) 27.

[10] A.B. Shelekhin, A.G. Dixon, Y.H. Ma, AIChE J. 41 (1995) 58.

[11] J. Ramsay, A.G. Fendler, A. Julbe, J.-A. Dalmon, French Patent No. 005652 (1994).

[12] A. Giroir-Fendler, J. Peureux, H. Mozzanega, J.-A. Dalmon, Stud. Surf. Sci. Catal. 101 (1996) 127.

[13] H. Moueddeb, P. Ciavarella, S. Miachon, J.-A. Dalmon, J. Membr. Sci. submitted for publication.

[14] W.J.W. Bakker, L.J.P.V.D. Broeke, F. Kapteijn, J.A. Moulijn, AIChE J. 43 (1997) 2203.

[15] H.H. Funke, A.M. Argo, J.L. Falconer, R.D. Noble, Ind. Eng. Chem. Res. 36 (1997) 136

[16] Z.A.E.P. Vroon, K. Keizer, A.J. Burggraaf, H. Verweij, J. Membr. Sci. 144 (1998) 65.

[17] Y. Yan, M.E. Davis, G. Gavalas, J. Membr. Sci. 123 (1997) 95.

[18] K. Kusakabe, S. Seiki, A. Murata, S. Morooka, J. Membr. Sci. 116 (1996) 39. 
[19] T. Sano, S. Ejiri, K. Yamada, Y. Kawakami, H. Yanagishita, J. Membr. Sci. 123 (1997) 225.

[20] M. Lovallo, M. Tsapatsis, AIChE J. 42 (1996) 3020.

[21] N. Nishiyama, K. Ueyama, M. Matsukata, Microporous Mater. 7 (1996) 299.

[22] K. Kusakabe, T. Kuroda, A. Murata, S. Morooka, Ind. Eng. Res. 36 (1997) 649.

[23] T. Masuda, H. Hara, M. Kouno, H. Kinoshita, K. Hashimoto, Microporous Mater. 3 (1995) 565.

[24] H. Kita, K. Horii, Y. Ohtoshi, K. Tanaka, K.-I. Okamoto, J. Mater. Sci. Lett. 14 (1995) 206.

[25] K. Aoki, K. Kukasabe, S. Morooka, J. Membr. Sci. 141 (1998).

[26] J.E. Lewis, G.R. Gavalas, M. Davis, AIChE J. 43 (1997) 83.

[27] R.M. Barrer, J. Chem. Soc., Faraday. Trans. 86 (1990) 1123.

[28] J. Xiao, J. Wei, Chem. Eng. Sci. 47 (1992) 1123.

[29] R. Krishna, J.A. Wesselingh, Chem. Eng. Sci. 52 (1997) 861.

[30] E.R. Geus, H.v. Bekkum, W.J.W. Bakker, J.A. Moulijn, Microporous Mater. 1 (1993) 131.

[31] E. Piera, A. Giroir-Fendler, J.A. Dalmon, H. Moueddeb, J. Coronas, M. Mendez, J. Santamaria, J. Membr. Sci. 142 (1998) 97.

[32] R. Soria, Catal. Today 25 (1995) 285.

[33] C. Bai, M.-D. Jia, J.L. Falconer, R.D. Noble, J. Membr. Sci. 105 (1995) 79.
[34] J.C.S. Wu, D.F. Flowers, P.K.T. Liu, J. Membr. Sci. 77 (1993) 85.

[35] P.B. Weisz, CHEMTECH 3 (1973) 498.

[36] A.J. Burggraaf, Z.A.E.P. Vroon, K. Keizer, H. Verweij, J. Membr. Sci. 144 (1998) 77.

[37] F. Kapteijn, W.J.W. Bakker, G. Zheng, J.A. Moulijn, Microporous Mater. 3 (1994) 227.

[38] F. Kapteijn, W.J.W. Bakker, G. Zheng, J. Poppe, J.A. Moulijn, Chem. Eng. J. 57 (1995) 145.

[39] W.J.W. Bakker, F. Kapteijn, J. Poppe, J.A. Moulijn, J. Membr. Sci. 117 (1996) 57.

[40] J. Kärger, D.M. Ruthven, Diffusion in Zeolites and Other Microporous Materials, Wiley, New York, 1992.

[41] B. Millot, A. Méthivier, H. Jobic, H. Moueddeb, M. Bée, J. Phys. Chem., in press.

[42] W. Zhu, J.M.v.d. Graaf, L.J.P.v.d. Broeke, F. Kapteijn, J.A. Moulijn, Ind. Eng. Chem. Res. 37 (1998) 1934.

[43] R. Hufton, R.P. Danner, AIChE J. 39 (1993) 954.

[44] H. Thamm, Zeolites 7 (1987) 341.

[45] B. Millot, Thèse, Université Claude Bernard Lyon 1, Lyon, 1998.

[46] J.M.V.d. Graaf, F. Kapteijn, J.A. Moulijn, J. Membr. Sci. 144 (1998) 87.

[47] N.-K. Bär, H. Jobic, J. Kärger, in preparation.

[48] R. Khan, E.C.d. Laro, E. Vinnet, J. Chem. Phys. 91 (1989) 5097. 